\title{
Evaluation of Variables According to Agility, Speed, and Power to the Type of Sand of Different Beaches for the Practice of Beach Volleyball
}

\author{
Julio Cesar de Faria Pastore ${ }^{1}$, Carlos Alberto de Azevedo Ferreira ${ }^{2}$, Fabíola Claudia \\ Henrique da $\operatorname{Costa}^{3}$, Paulo Vicente João ${ }^{4}$ \\ ${ }^{1,2}$ Physical Education, Estácio de Sá University - Rio de Janeiro - Brazil; Laboratory of Physiology \\ of Exercise \& Measurements and Evaluation (LAFIEX), Estácio de Sá University - Rio de Janeiro - \\ Brazil; Research Center in Sports Science, Health and Human Development (CIDESD), University of \\ Tras-os-Montes and Alto Douro - Vila Real - Portugal \\ ${ }^{3,4}$ Research Center in Sports Science, Health and Human Development (CIDESD), University of \\ Tras-os-Montes and Alto Douro - Vila Real - Portugal
}

\begin{abstract}
This study aimed to evaluate the density and the effect of the sand characteristics on the physical parameters in Beach Volleyball athletes, the researcher developed an instrument pilot following the standard of the Brazilian Association of Technical Standards (ABNT, MB-1059/86) for measuring the density of sand in situ. This study formed part eighteen $(n=18)$ female athletes from Brazil, with a mean age of $24 \pm 4.35$ years, height $1.76 \pm 0.05$ meter, federated with a year of competition in the Circuit Bank of Brazil and World Tour. The study evaluated three physical abilities and their relation to the density of sand in two different places (beaches of Ipanema and Barra - Rio de Janeiro) in athletes practicing volleyball. According to the objectives proposed in the introduction and the results became evident that the type of sand did not affect the indicators associated with physical valences studied, agility, speed, and power. However, with the tests, it was possible to create a possible profile of the female athlete in the Brazilian beach volleyball.
\end{abstract}

Keywords: Sand Land, Functional Profile, Beach Volleyball, Agility, Speed, Power.

\section{INTRODUCTION}

Beach volleyball, over the years, has undergone variations in its rules and conducting new research in search of a better athletic performance. In Brazil, this sport has evolved in a great way, becoming a school in the world-wide sports scene, where the Brazilian teams have achieved great prominence in all categories, being now record holder of international titles ${ }^{1 .}$

Based on this assumption ${ }^{1}$, cites in his studies that specific training execution capabilities to enhance athletes performance during a match come from the ability of explosive strength, agility and speed. $^{2,3,4,5,6,7}$

Considering that the expression of these physical capacities occurs in an irregular sand with the possibility of being characterized by different densities, the present study has the objective of investigating the influence of the sand characteristics on the performance of the agility, speed, launched speed and power physical valences in different locations of training and, consequently, to establish benchmarks for assessing these valences to date that do not exist for this type of sand ${ }^{1}$.

This premise is evidenced in studies developed in other sports ${ }^{8}$ when it was shown that the terrain directly influences the maintenance of effort intensity in running speed work. In another study with field soccer athletes, a difference in running speed was observed on dry and wet lawns ${ }^{9}$. The literature suggests that this phenomenon also occurs when the intensity of other physical valences between hard surface and sand. ${ }^{10,11,12,13 \text {. }}$

Lejeune, Willems, and Heglund ${ }^{8}$ analyzed comparisons between walking and running on terrains with different characteristics and density. A force platform and kinematic analysis were used to determine the mechanical work done by humans during walking and running on sand and on a hard surface. Walking in the sand requires 1.6-2.5 times more mechanical work than walking on a hard surface at 
the same speed. In contrast, running in the sand requires only 1.15 times more mechanical work than not running on a hard surface at the same speed. Walking in the sand requires 2.1-2.7 times more energy than walking on a hard surface with the same speed; in turn, running in the sand requires 1.6 times more energy than running on a hard surface. This led the authors to believe that the increase in energy cost is mainly due to two effects: the mechanical work done in the sand, and a decrease in the positive work efficiency done by muscles and tendons.

As the World Circuit is played on several continents, different countries and almost always, where the places of competition are performed on beaches, mostly artificial or built for the purpose, we think it necessary to accomplish this assessment to the possible types of sand.

The aim of the research was to verify if differences in the characteristics of sand density generate influences on the performance of beach volleyball athletes.

\section{Materials \& Methods}

Inclusion criterion was randomly selected eighteen $(n=18)$ beach volleyball female athletes, between the ages of 20 and $32(24.0 \pm 4.35$ years $)$, height (1.76 \pm 0.05 meters) and Body Mass $(66.5 \pm 5.4 \mathrm{~kg})$ who trained on the beaches of South zone of Rio de Janeiro, federated participants of the Circuit Bank of Brazil Beach Volleyball and World Circuit Beach Volleyball, for at least one year. However, as an exclusion criterion, it was determined that athletes who did not test on both beaches or were injured during the collection period would be prevented from continuing. Three physical capacities were evaluated in two distinct beaches (Ipanema and Barra - Rio de Janeiro). The capabilities analyzed were agility, speed, launched speed and power.

The physical tests adopted followed the standardization determined by the study of Pastore et. $\mathrm{al}^{1}$.

\subsection{Intervening Factors}

External factors such as temperature, humidity, barometric pressure and climate were recorded by the researcher although it was not possible to interfere.

\subsection{Description of the Experimental Evaluation}

The tests were performed in the morning, between 8:00 and 10:00 a.m., considering that most of the training takes place at the same time. Before and after the experiments, barometric pressure (Polar model ANX 500, Finland), relative air humidity (Incoterm Thermo-Hygrometer, 5203.03, Brazil) and temperature (Barometer Oregon, EB312E, USA) were recorded. In addition, 4,712 $\mathrm{cm} 3$ of sand were collected, for the measurement of its mass (Filizola Balance, MF 6/1, Brazil) from which the density of the sand was calculated.

Following the objective of studying the effect of the sand characteristics on the physical parameters, the tests were performed on two occasions in two beach volleyball courts located in distinct districts of Rio de Janeiro. In this sense, for the evaluation of sand density, an instrument was developed following the Brazilian Association of Technical Standards (ABNT, MB-1059/86) standard for measuring sand specific mass in situ, using a drilling cylinder, Which is only applicable to finegrained sand, free from boulders, cohesive and not very hard, under norm number 9813/1987 of the Brazilian Registered Standard (NBR).

As shown in Figure 1, it has as characteristics an acrylic guide cube of 1 centimeter $(\mathrm{cm})$ in thickness and $15 \mathrm{~cm}$ in side (C) and in the upper part a center opening with a diameter of $12 \mathrm{~cm}$, where a $60 \mathrm{~cm}$ long cylindrical polyvinyl chloride (PVC) crimping tube with a diameter of $10 \mathrm{~cm}$ is passed and its upper part is open for air passage (B), the crimping socket (A) has been machined in iron with a base of $20 \mathrm{~cm}$ in diameter and $2 \mathrm{~mm}$ thick with a fixed tube at the top of $20 \mathrm{~cm}$ inlength.

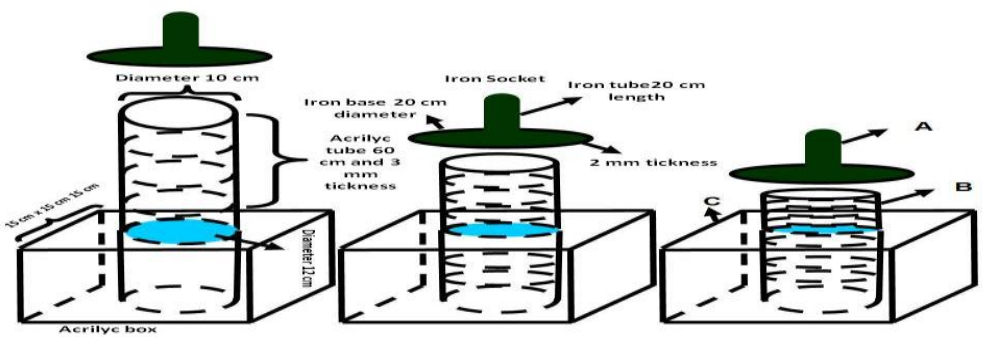

Figure1. Densitometer illustration: An instrument developed for the evaluation of sand density and drilling process for the measurement of sand density. 
The natural mass density $\left(Y_{h}\right)$ of the sand in situ was calculated according to the expression:

$$
Y_{h}=\frac{M_{t}-M_{c}}{V_{c}}
$$

Where, $\mathbf{M}_{\mathbf{t}}$ is the mass of the cylinder with the sample wet or dry, in grams (g); $\mathbf{M}_{\mathbf{c}}$ is the mass of the cylinder, in $\mathrm{g}$; and $\mathbf{V}_{\mathbf{c}}$ is the cylinder's internal volume, in $\mathrm{cm}^{3}$.

Execution of the test followed chronologically the ABNT standard (MB-1059/86), as summarized in Table 1.

Table1. Test run sequence

\begin{tabular}{l} 
* The crimping cylinder is set in the guide box so that it touches the surface of the ground properly leveled and \\
free of loose particles. \\
\hline * The crimping of the cylinder was started by beating the iron socket, taking care to keep the cylinder in the \\
upright position. \\
* The crimping was continuous until the cylinder had its entire body full of the harvested material. \\
\hline * The guide box was removed and the surrounding ground was excavated to the cylinder. The sand was cut \\
beneath the cylinder of its lower edge using a spatula to close the cylinder therewith. \\
* The mass of the cylinder containing the material, Mt, was determined immediately, in order to avoid loss of \\
moisture, with a resolution of 1 gramme (g). The specimen was then removed from the cylinder and the center of \\
the specimen by taking a sample for determination of the moisture content, h, using a scale which allowed a \\
nominal weight of $1,5 \mathrm{~kg}$ to $10 \mathrm{~kg}$, With resolution of 0.1 to $1 \mathrm{~g}$, respectively, and compatible sensitivities \\
according to NBR 6457 (Brazilian Standard Registered, 1987).
\end{tabular}

NBR 6457 (Brazilian Standard Registered, 1987).

\subsection{Statistical Treatment}

For the analysis and treatment of the data, the present study made use of the descriptive statistics with the measures of central tendency and dispersion (mean, median, standard deviation, and variance) and verification of the normality of the sample through the Shapiro-Wilk test. As inferential analysis, asymmetry and kurtosis calculations were used to verify the distribution of the data. From the study of the normality of the data, we will make the comparison of the density of the sand and its respective effects in the performance of the agility, speed, launched speed and power with the comparison test of average more suitable for the design of the study.

For the inferential analysis of the comparison of the different types of sand, Student's "T" Test was performed, according to normality; to identify the interference of the sand type in the performance results in the agility, power, and speed tests, being the same tests used to the beaches. Finally, a Pearson correlation was performed to compare the heart rate response to the result of each test, according to the normality of the sample, taking into account the error estimate and the confidence level, the confidence level for data analysis was $\mathrm{p}<0.05$. Data were analyzed using the statistical package SPSS ${ }^{\circledR}$ version 23.0 for Windows ${ }^{\circledR}$.

\section{RESULTS}

The anthropometric characteristics of the group in the present study presented values for Age (24.0 \pm $4.5)$ years, Body Mass $(66.5 \pm 5.4) \mathrm{kg}$, Height $(1.76 \pm 0.05)$ meters, BMI $(21.6 \pm 1.6) \mathrm{kg} / \mathrm{m}^{2}$, Sum of 7 skinfolds $(89.8 \pm 15.2)$ millimeters, \% Fat $(17.2 \pm 2.5) \%$ and Body Density $(1.059 \pm 0.005) \mathrm{g} / \mathrm{cm}^{3}$.

In the anthropometric characteristics of the group, it was possible to detect in relation to the age that the group presented a considerable dispersion in this variable, as verified by the coefficient of variation (19\%). Considering that the group is female, this characteristic exerts a considerable influence on the fat percentage variable $(\% \mathrm{G})$, and that the female athlete herself has a characteristic of every five years to modify her anthropometric profile.

With regard to perimeter of the circumferences, the values of Thorax (81.6 \pm 5.1$)$, Abdomen (80.5 \pm 5.4), Right Arm (28.8 \pm 1.8 ), Left Arm (28.3 \pm 1.8$)$, Right Thigh (58.5 \pm 3.5$)$, Left Thigh (58.2 \pm 3.6 ), Right Leg $(35.3 \pm 2.4)$, and Left Leg $(35.3 \pm 2.3)$ where all the results of each test are presented in centimeters.

For the skinfolds, the values of average Axillary (7.8 \pm 2.8$)$, Subscapular $(9.5 \pm 2.2)$, Triceps (13.8 \pm $3.1)$, Suprailiac $(12.5 \pm 3.9)$, Abdomen $(16.2 \pm 4.5)$, Thigh $(17.1 \pm 3.9)$ and Leg (12.8 \pm 2.7$)$. The results are all expressed in millimeters. 
We observed that the regions of greatest accumulation of subcutaneous fat were to the thigh and the abdomen. It is worth noting that volleyball presents a predominant anaerobic characteristic, making it difficult to mobilize body fat, making it slower to mobilize subcutaneous deposits ${ }^{15}$.

The relative humidity of the initial air $(83.3 \pm 10.5) \%$, relative humidity of the final air $(74.4 \pm 9.3) \%$, was related to the values collected in relation to the ambient conditions in Ipanema beach, initial air temperature $(19.5 \pm 3.3)$ degrees, final air temperature $(24.5 \pm 3.3)$ degrees, barometric pressure (766.2 \pm 2.1$) \mathrm{mmHg}$, sand weight $(7.0 \pm 0.3) \mathrm{kg}$, Climate $(1.4 \pm 0.5)$, where the climatic situation (1sun and 2-cloudy), sand volume (4712.4) $\mathrm{cm}^{3}$, and sand density $(1.374 \pm 0.070) \mathrm{g} / \mathrm{cm}^{3}$.

The environmental conditions found on Ipanema beach, henceforth called beach one (1), were of the average barometric pressure of $766 \mathrm{mmHg}$, sand density of $1,374 \mathrm{~g} . \mathrm{cm} 3$, which were considered as intervening factors in the performance (According to Table 2).

Table 2 - Mean values and standard deviation of the environmental conditions: initial air (IA) and final air $(F A)$, initial air temperature (IAT) and final air temperature (FAT), barometric pressure in mmHg (BP), sand weight (kg), climatic situation (1- sun, 2- cloudy), sand volume $(\mathrm{SV})\left(\mathrm{cm}^{3}\right)$ and sand density $(\mathrm{SD})(\mathrm{g} \mathrm{cm})$.

\begin{tabular}{|c|c|c|c|c|c|c|c|c|}
\hline \multicolumn{9}{|c|}{ IPANEMA BEACH } \\
\hline & Mean & SD & Coef. Var. & Medium & Maximum & Mínimum & kurtosis & Asimmetry \\
\hline IA (\%) & 83.3 & 10.5 & 0.13 & 85.0 & 94.0 & 60.0 & 0.9 & -1.1 \\
\hline FA $(\%)$ & 74.4 & 9.3 & 0.12 & 77.0 & 82.0 & 53.0 & 1.4 & -1.5 \\
\hline IAT $\left(^{\circ}\right)$ & 19.5 & 3.3 & 0.17 & 18.0 & 29.0 & 17.0 & 5.9 & 2.3 \\
\hline FAT $\left(^{\circ}\right)$ & 24.5 & 3.3 & 0.13 & 23.0 & 34.0 & 22.0 & 6.4 & 2.3 \\
\hline BP (mmHg) & 766.2 & 2.1 & 0.00 & 765.9 & 768.1 & 763.3 & -1.6 & -0.4 \\
\hline Sand Weight (kg) & 7.0 & 0.3 & 0.05 & 7.2 & 7.3 & 6.6 & -1.8 & -0.4 \\
\hline Climatic Situation & 1.4 & 0.5 & 0.36 & 1.0 & 2.0 & 1.0 & -1.9 & 0.6 \\
\hline $\mathrm{SV}\left(\mathrm{cm}^{3}\right)$ & 4712.4 & 0.0 & 0.00 & 4712.4 & 4712.4 & 4712.4 & -2.3 & 1.1 \\
\hline SD $\left(\right.$ g.cm $\left.^{3}\right)$ & 1.37464 & 0.07010 & 0.05 & 1.42391 & 1.44152 & 1.28491 & -1.83185 & -0.35795 \\
\hline
\end{tabular}

Standard deviation (sd), Coefficient of variation (coef. var.)

Regarding the climatic conditions measured at Barra beach, the results showed such values:

Relative air humidity initial $(83.4 \pm 3.9) \%$, Relative air humidity final $(79.6 \pm 2.7) \%$, initial temperature $(20.8 \pm 2.0)$ degrees, final temperature $(26.2 \pm 3.5)$ degrees, barometric pressure $(760.6 \pm$ $3.7) \mathrm{mmHg}$, sand weight $(6.7) \mathrm{kg}$, climate $(1.4 \pm 0.5)$, sand volume (4712.4) $\mathrm{cm}^{3}$ and sand density $(1.303 \pm 0.009)$.

The environmental conditions found in the Barra beach, henceforth called beach two (2), were of the barometric pressure of $760.6 \mathrm{mmHg}$, sand density of $1.303 \mathrm{~g} . \mathrm{cm}^{3}$ factors considered to be intervening in performance (According to Table 3).

Table 3 - Mean values and standard deviation of the environmental conditions: initial air (IA) and final air (FA), initial air temperature (IAT) and final air temperature (FAT), barometric pressure in mmHg (BP), sand weight $(\mathrm{kg})$, climatic situation (1- sun, 2- cloudy), sand volume (SV) $\left(\mathrm{cm}^{3}\right)$ and sand density (SD) $\left(\mathrm{g} \mathrm{cm}^{3}\right)$.

\begin{tabular}{|c|c|c|c|c|c|c|c|c|}
\hline \multicolumn{9}{|c|}{ BARRA BEACH } \\
\hline & Mean & SD & Coef. Var. & Medium & Maximum & Minimum & kurtosis & Asimmetry \\
\hline IA (\%) & 83.4 & 3.9 & 0.05 & 83.0 & 88.0 & 77.0 & -0.7 & -0.6 \\
\hline FA (\%) & 79.6 & 2.7 & 0.03 & 80.0 & 82.0 & 75.0 & -0.6 & -0.9 \\
\hline IAT $\left(^{\circ}\right)$ & 20.8 & 2.0 & 0.10 & 20.0 & 24.0 & 19.0 & -1.3 & 0.6 \\
\hline FAT I( $\left.{ }^{\circ}\right)$ & 26.2 & 3.5 & 0.13 & 25.0 & 30.0 & 22.0 & -1.9 & 0.1 \\
\hline BP (mmHg) & 760.6 & 3.7 & 0.00 & 759.0 & 767.1 & 757.5 & -0.2 & 1.2 \\
\hline Sand Weight (kg) & 6.7 & 0.0 & 0.01 & 6.7 & 6.7 & 6.6 & -0.7 & 0.8 \\
\hline Climatic Situation & 1.4 & 0.5 & 0.36 & 1.0 & 2.0 & 1.0 & -1.9 & 0.6 \\
\hline SV $\left(\mathrm{cm}^{3}\right)$ & 4712.4 & 0.0 & 0.00 & 4712.4 & 4712.4 & 4712.4 & -2.3 & 1.1 \\
\hline SD $\left(\right.$ g.cm $\left.{ }^{3}\right)$ & 1.30388 & 0.00923 & 0.01 & 1.29998 & 1.31929 & 1.29446 & -0.74210 & 0.81310 \\
\hline
\end{tabular}

Standard deviation (sd). Coefficient of variation (coef. var.)

The results of the tests performed at Ipanema beach presented the following data: Agility $(6.97 \pm$ $0.39)$, Speed (3.26 \pm 0.22$)$, Launched Speed (2.81 \pm 0.25$)$ and Power (3.02 \pm 0.37$)$. Consequently, the same tests performed at Barra beach presented the following values: Agility $(6.91 \pm 0.40)$, Speed (3.30 \pm 0.21$)$, Launched Speed $(2.87 \pm 0.35)$ and Power $(3.11 \pm 0.40)$ where all the results of each test are presented in seconds (Tables 4 and 5). 
Evaluation of Variables According to Agility, Speed, and Power to the Type of Sand of Different Beaches for the Practice of Beach Volleyball

Analyzing Tables 2 and 3, it was possible to verify that there is a significant difference between the climatic conditions of a barometric pressure of Barra and Ipanema beaches, as well as the pressure of the beach of Barra, is smaller between both. The environmental conditions of sand density and sand weight also present a significant difference, being that the beach of Barra is smaller than that of Ipanema.

Table4. Mean values and standard deviation of the tests obtained in female beach volleyball athletes.

\begin{tabular}{|c|c|c|c|c|c|c|c|c|}
\hline \multicolumn{10}{|c|}{ IPANEMA BEACH } \\
\hline & Mean & SD & Coef. Var. & Medium & Minimum & Maximum & kurtosis & Asimmetry \\
\hline Agility & 6.97 & 0.39 & 0.06 & 7.10 & 6.10 & 7.44 & 0.58 & -1.12 \\
\hline Speed & 3.26 & 0.22 & 0.07 & 3.26 & 2.94 & 3.91 & 2.87 & 1.28 \\
\hline L. Speed & 2.81 & 0.25 & 0.09 & 2.79 & 2.34 & 3.50 & 2.79 & 1.02 \\
\hline Power & 3.02 & 0.37 & 0.12 & 2.92 & 2.37 & 3.71 & -0.70 & 0.16 \\
\hline
\end{tabular}

Launched Speed (L. Speed). Standard deviation (sd). The coefficient of variation (coef. var.)

Table5. Mean values and standard deviation of the tests obtained in female beach volleyball athletes.

\begin{tabular}{|l|l|l|l|l|l|l|l|l|}
\hline \multicolumn{9}{|c|}{ BARRA BEACH } \\
\hline & Mean & SD & Coef. Var. & Medium & Minimum & Maximum & Kurtosis & Asimmtry \\
\hline Agility & 6.91 & 0.40 & 0.06 & 7.02 & 5.64 & 7.33 & 4.64 & -1.90 \\
\hline Speed & 3.30 & 0.21 & 0.07 & 3.27 & 3.04 & 3.92 & 2.96 & 1.60 \\
\hline L. Speed & 2.87 & 0.35 & 0.12 & 2.82 & 2.27 & 3.64 & 0.90 & 0.85 \\
\hline Power & 3.11 & 0.40 & 0.13 & 3.00 & 2.38 & 3.78 & -1.10 & 0.20 \\
\hline
\end{tabular}

Launched Speed (L. Speed). Standard deviation (sd). The coefficient of variation (coef. var.)

It is possible to observe in table 6 that there was an inference between the environmental conditions of the two beaches with the use of Student's "T" test. The mean environmental conditions were significantly different $(\mathrm{p}<0.05)$. Where only relative humidity measured initially at the tests did not present significant difference.

When observing the tables 4 and 5 it is verified that the differences of the beach of Barra exerted influence in the tests of speed, speed launched and power realized in both beaches. Due to the lower sand density and sand weight conditions in Barra beach, they consequently generated a worse result.

Table6. Comparison of the values of the environmental characteristics between the Ipanema and Barra beaches

\begin{tabular}{|c|c|}
\hline Test "T" & $\boldsymbol{P .}$ \\
\hline SD & $\mathbf{0 . 0 0 0 *}$ \\
\hline SW (kg) & $\mathbf{0 . 0 0 0 *}$ \\
\hline IA & 0.968 \\
\hline FA & 0.024 \\
\hline BP & $\mathbf{0 . 0 0 0 *}$ \\
\hline
\end{tabular}

Initial air (IA). Final air (FA). Barometric Pressure (BP)

Sand Weight (SW). Sand Density $(S D)$. ( $p<0.05)$

As can be seen in table 7, there are differences in the barometric pressure in the heat rate (HR) test relative to the maximum speed, as well as in the mean HR relative to speed and mean power HR. It was also observed in the HR maximum relative to the agility and the average temperature, as in the HR maximum, relative to the power at the mean temperature and, finally, the reserve HR relative to the average temperature.

Table7. Estimation of Pearson correlation for environmental and maximum. medium and reserve heart rate for agility. speed. and power

\begin{tabular}{|l|l|l|l|}
\hline \multicolumn{5}{|c|}{ VALUE - p } & BP \\
\hline Variables & RU. Av. & T. Av. & $-\mathbf{0 . 1 2 5}$ \\
\hline HR.Mx.Agility & $\mathbf{0 . 0 8 1}$ & $-\mathbf{0 . 0 2 8} *$ & $\mathbf{0 . 0 2 4}$ \\
\hline HR.Mx.Speed & $\mathbf{0 . 1 2 5}$ & $\mathbf{0 . 1 4 7}$ & $\mathbf{0 . 0 8 7}$ \\
\hline HR.Mx.Power & $-\mathbf{0 . 1 2 2}$ & $\mathbf{0 . 0 1 9}$ & $-\mathbf{0 . 0 1 0 ^ { * }}$ \\
\hline HR.Md.Speed & $\mathbf{0 . 1 2 4}$ & $\mathbf{- 0 . 2 4 0}$ & $\mathbf{0 . 0 1 1}$ \\
HR.Md.Power & $\mathbf{- 0 . 0 1 7}$ & $\mathbf{- 0 . 1 6 6}$ & $\mathbf{- 0 . 1 1 9}$ \\
HR. Reserve & $-\mathbf{0 2 4 9}$ & $\mathbf{0 . 0 4 2}$ & \\
\hline
\end{tabular}

Relative humidity average (RU. Av.) Temperature average (T. Av.)

Heart Rate Maximum (HR.Mx).

Heart Rate Medium (HR. Md). ( $\mathrm{p}<0.05)$ 


\section{DISCUSSION}

After years of training on several beaches across continents, it is well known that the types of sand are different because the description of the athletes themselves says they can jump more or less, depending on the type of sand. In this sense, with this investigation, we wanted to try to understand if through the physical tests applied could prove these differences in function of the different types of sands of different beaches.

According to the researched literature, it did not present any analysis of the physical and functional characteristics of a beach volleyball game. Another study with 26 female volleyball athletes presented the following data for the agility test (agility T-Test) coefficient of $(0.762)$ and in the power test (vertical jump) the coefficient found was $(0.932)^{14}$.

However, the study by Leite ${ }^{16}$, who observed 13 subjects with an average of $19.46 \pm 2.82$ years of Le Parkour practice in which they were, evaluated in the squat jump test with a mean of $55.96 \pm 5.31 \mathrm{~cm}$. The results found for Le Parkour practitioners in this study were superior to those of Street Skate practitioners with at least two years of practice, whose mean value was $46.7 \pm 8.3 \mathrm{~cm}$. This suggests that the practice of Le Parkour develops the power of lower limbs due to being an acyclic activity like beach volleyball.

A study that was conducted with 11 indoor volleyball athletes with an average of 15.9 years detected as results for the agility test the average of 6.59 seconds $^{17}$.

Vieira ${ }^{7}$ researched 9 volleyball athletes and found the means for the agility of 0.32 seconds $(\mathrm{sec})$ and for the power test of 0.02 centimeters $(\mathrm{cm})$.

On the order hand, Dourado ${ }^{18}$ conducted a study in which 12 male volleyball players with an intentional average of $17.76 \pm 0.71$ years were evaluated, who underwent physical training for seventeen weeks, totaling 94.92 hours of preparation and observed for $(\mathrm{P}=0.000)$ And the jump power test $)(\mathrm{p}=0.790)$.

In another research was evaluated 40 volleyball athletes performing the power test (vertical jump test - Sargent Test adapted) resulting in the first group composed of 21 athletes $43.58 \pm 5.32 \mathrm{~cm}$ and the second group composed of 19 athletes $44.47 \pm 3.67 \mathrm{~cm}$. It is observed that the explosive strength of the lower limbs quantified by the height of the vertical jump, did not present significant difference between the groups ${ }^{19}$.

Conformed the study by Silva-Junior ${ }^{20}$, aimed to examine the correlations between sprints of 10 and 30 meters and vertical jump power in young soccer players. A total of 143 male soccer players from the Under-20 $(n=34)$, Under-17 $(n=43)$ and Under-15 $(n=66)$ males participated in the study, and sprints of 10 and 30 meters. The results found presented low to moderate correlations when comparing the absolute values of time and height achieved $(\mathrm{r}=.47$ to .71$)$.

Nevertheless in another research ${ }^{8}$ was analyzed comparatives between walking and running on terrains with different characteristics and density. Force platform and film analysis were used to determine the mechanical work done by humans during walking and running in the sand and on a hard surface. Walking in the sand requires 1.6-2.5 times more mechanical work than walking on a hard surface at the same speed.

In contrast, running in the sand requires only 1.15 times more mechanical work than not running on a hard surface at the same speed. Walking in the sand requires 2.1-2.7 times more energy than walking on a hard surface with the same speed; in turn, while running in the sand requires 1.6 times more energy than running on a hard surface. This led the authors to believe that the increase in energy cost is mainly due to two effects: the mechanical work done in the sand, and a decrease in the positive work efficiency done by muscles and tendons.

In spite of these findings in the literature, in the present study within the evaluations performed (agility, speed, and power), there are no clear significant differences, we think that the meteorological conditions (temperature, barometric pressure, among others) may condition the athletes (such as humidity) among others.

However, it was not possible to identify with certainty the proposed study objectives with certainty, but according to the reports of coaches and athletes, these different and pioneering evaluations in 
beach volleyball could help improve the quality of physical work, as well as the type of sand or beach to use so that it can be as close as possible to the reality of the competition and can help to improve the conditions of practice and future success.

\section{CONCLUSION}

According to the objectives proposed in the introduction and with the presented results, it was evident that the type of sand did not interfere in the indicators associated with the studied physical valences, agility, speed, launched speed and power.

However, there seems to be a direct finding in the results regarding some variables, regarding the barometric pressure and the average temperature in relation to the speed, agility and power and even the Heart Rate of reserve found in the present investigation.

It is necessary to reiterate that the methodology used here was specially developed for this pilot study. It can be improved in view of the interest of each research that is carried out, but that the data contained herein may serve the professionals who practice the modality as a reference for future works with similar purposes.

Therefore, it is with this type of work based on other areas of intervention that possible new indicators can be found and at the same time, small starting points to improve the performance of the athletes. Gradually this information can make the difference between winning and losing.

This research team intends to improve the information so that new indicators can be found to stimulate the teams present at the upcoming 2020 Olympics in Japan. To do so, a possible investigation on the next world circuit may be a key point.

\section{REFERENCES}

[1] Pastore JCF, Ferreira CAA, Da Costa FCH, João PV. Case Study: Proposal for Training in Combined Plyometrics and Muscular Strength in Improved Vertical Jump in Beach Volley: International Journal of New Technology and Research (IJNTR). 2015: (2): 30-33.

[2] Kraemer WJ, Hakkinen K. Strength training for sport. Blackwell Science. Iowa: USA. 2002.

[3] Ré AHN. Relações entre crescimento, desempenho motor, maturação biológica e idade cronológica em jovens do sexo masculino. Revista Brasileira de Educação Física e Esporte, São Paulo. 2005; 19(2): 153-62.

[4] Carvalho C, Carvalho A. Não se deve identificar força explosiva com potência muscular, ainda que existam algumas relações entre ambas. Rev. Port. Cien. Desp. 2006; 6(2): 241-248.

[5] Lopes MR, Chagas Neto PB, Campos FAD, Silveira ACMB, Rocha MA. Análise dos tempos de jogos no voleibol masculino - campeonato Brasileiro infanto-juvenil do ano de 2002. In: XXVI Simpósio Internacional de Ciências do Esporte. Revista Brasileira de Ciência e Movimento. 2003; 26: 19.

[6] Hespanhol JE, Neto LGS. A resistência de força explosiva em jovens voleibolistas do sexo masculino. Movimento \& Percepção, Espírito Santo de Pinhal, SP, 2006; 6(8).

[7] Vieira NA. Efeito do treinamento de resistência de força no sistema neuromuscular em atletas de voleibol. Revista Conexões, Campinas, 2008; 6: 83-95.

[8] Lejeune TM, Willems PA, Heglund NC. Mechanics and energetics of human locomotion on the sand. The Journal of Experimental Biology. 1998; 201: 2071-2080.

[9] Santana JC. Movement in the sand: Training implications for beach volleyball. National Strength and Conditioning Association. 2006; 28(5): 19-21.

[10] Cetolin T. Diferença entre intensidade do exercício prescrita por meio do teste TCAR no solo arenoso e na grama. Rev Bras Cineantropom Desempenho Hum. 2010; 12(1): 29-35.

[11] Sannicandro I, Colella D, Anna Rosa R, Morano M. Motion skills on soft sand and conventional surface in beach soccer. J Sport Sci Med. 2007; 6(10): 169.

[12] Moreira GMD. A influência de um gramado molhado sobre o desempenho em um teste progressivo para jogadores de futebol. [Dissertação de Mestrado - Programa de Pós Graduação em Educação Física]. Caxias do Sul (RS): Universidade de Caxias do Sul 2001. 
[13] Zamparo P, Perini R, Orizio C, Sacher M, Ferretti G. The energy cost of walking or running on sand. Eur J Applied Physiol.1992; 65(2): 183-187.

[14] Schall ML. Physiologic performance test differences by competition level and player position in female volleyball athletes. Thesis for the degree of Master of Science in Exercise and Sports Studies, Biophysical Studies Boise State University. 2011.

[15] Tavares ÓM, Valente-dos-Santos J, Duarte JP, et al. Concurrent agreement between an anthropometric model to predict thigh volume and dual-energy X-Ray absorptiometry assessment in female volleyball players aged 14-18 years. BMC Pediatrics. 2016; (16):190.

[16] Leite N. Perfil da Aptidão Física dos Praticantes de Le Parkour. Rev Bras Med Esporte. 2011; 17(3): 198-201.

[17] Levandoski G, Cardoso FL, Cieslak F. Perfil somatótipo, variáveis antropométricas, aptidão física e desempenho motor de atletas juvenis de voleibol feminino da cidade de Ponta Grossa / PR. Fit Perf J. 2007; 6(5): 309-14.

[18] Dourado AC. Monitoração de adaptações antropométricas, motoras e modelação estrutura do desempenho esportivo de atletas de voleibol durante período de preparação. Tese de doutorado, Universidade do Rio grande do Sul. 2007.

[19] Cabral, BGAT. Efeito discriminante da morfologia e alcance de ataque no nível de desempenho em voleibolistas. Rev Bras Cineantropom Desempenho Hum. 2011; 13 (3): 223-229.

[20] Silva-Junior CJ. Relação entre as potências de sprint e salto vertical em jovens atletas de futebol. Motricidade. 2011; 7(4): 5-13.

Citation: Julio Cesar, de Faria Pastore et al. "Evaluation of Variables According to Agility, Speed, and Power to the Type of Sand of Different Beaches For the Practice of Beach Volleyball." International Journal of Sports and Physical Education (IJSPE), vol 3, no. 3, 2017, pp. 1-8. doi:http://dx.doi.org/10.20431/24546380.0303001.

Copyright: (ㅇ 2017 Authors. This is an open-access article distributed under the terms of the Creative Commons Attribution License, which permits unrestricted use, distribution, and reproduction in any medium, provided the original author and source are credited. 